\title{
Frecuencia de enteroparásitos en primates Cebidae y Callitrichidae del Zoológico de Cali, Colombia: implicaciones zoonóticas
}

Jorge Iván Zapata-Valencia', Sebastián Ortega-Valencia'1, Yisther Katherine SilvaCuero', Lina Sofía Castillo-Castillo', Laura Sofía Ortega-Ruiz¹, Adriana Cardona-Ortiz¹, Juliana Peña-Stadlin²

${ }^{1}$ Escuela de Bacteriología y Laboratorio Clínico, Facultad de Salud, Universidad del Valle, Cali, Colombia

${ }^{2}$ Área de Bienestar Animal, Fundación Zoológico de Cali, Cali, Colombia

Recibido: 06/02/2020

Aceptado: 30/03/2021

Publicado: 06/04/2021

Citación:

Zapata-Valencia JI, Ortega-Valencia S, Silva-Cuero YK, Castillo-Castillo LS, Ortega-Ruiz LS, CardonaOrtiz A, et al. Frecuencia de enteroparásitos en primates Cebidae y Callitrichidae del Zoológico de Cali, Colombia: implicaciones zoonóticas. Biomédica. 2021;41(Supl.1):60-81.

https://doi.org/10.7705/biomedica.5403

\section{Correspondencia:}

Jorge Iván Zapata-Valencia, Escuela de Bacteriología y Laboratorio Clínico, Facultad de Salud, Universidad del Valle, Campus de San Fernando, Calle 3A No 36B-05, edificio 134, Cali, Colombia

Teléfonos: (572) 5581929 y (301) 431 8380; fax: (572) 5140028

jorge.zapata@correounivalle.edu.co

\section{Contribución de los autores:}

Jorge Iván Zapata-Valencia: coordinación general de proyecto, lectura de láminas y análisis de datos Sebastián Ortega-Valencia: montaje de muestras, lectura de láminas y análisis de datos

Yisther Katherine Silva-Cuero, Lina Sofía CastilloCastillo, Laura Sofía Ortega-Ruíz, Adriana CardonaOrtiz: montaje de muestras, lectura de láminas y sistematización de datos

Juliana Peña-Stadlin: coordinación del proyecto en el Zoológico de Cali

Todos los autores participaron en la redacción, revisión y corrección del manuscrito.

Financiación:

La Fundación Zoológico de Cali apoyó este proyecto con el uso de equipos del Laboratorio Clínico del Zoológico de Cali y, el Laboratorio de Parasitología de la Escuela de Bacteriología y Laboratorio Clínico de la Universidad del Valle, con reactivos. La Fundación Zoológico de Cali facilitó la participación de los cuidadores de los animales en la toma de muestras y el salario de la investigadora Juliana Peña-Stadlin. El proyecto se hizo bajo la modalidad de presentación interna, por lo cual la Universidad del Valle permitió la asignación de tiempo para e investigador Jorge Iván Zapata-Valencia durante su desarrollo. Los demás gastos del proyecto corrieron por cuenta de los investigadores involucrados.

\section{Conflicto de intereses:}

Los autores manifiestan que no existen conflictos de intereses.
Introducción. Los enteroparásitos pueden generar problemas en animales bajo cuidado humano en zoológicos y centros de acogida. Los animales silvestres presentan bajas cargas parasitarias, pero estas pueden ser mayores y llevar a manifestaciones clínicas cuando se trata de animales resguardados en recintos, lo que aumenta los gastos en tratamientos y cuidados médicos. Por otro lado, algunos enteroparásitos pueden causar infecciones zoonóticas en los cuidadores, los visitantes y otros animales del zoológico, así como afectar los programas de recuperación de especies amenazadas de extinción. Objetivos. Determinar la presencia y prevalencia de enteroparásitos con potencial de transmisión zoonótica en primates de las familias Cebidae y Callitrichidae del Zoológico de Cali, entre septiembre y noviembre de 2017.

Materiales y métodos. Se hizo un estudio transversal prospectivo, para lo cual se recolectaron muestras seriadas de 50 individuos pertenecientes a siete especies de dos familias de primates y se analizaron mediante examen coprológico, flotación y coloración Kinyoun, entre septiembre y noviembre de 2017.

Resultados. Según su prevalencia, los géneros de parásitos hallados en las siete especies de primates evaluadas, fueron Blastocystis spp., Trichomonas spp., Giardia spp., Entamoeba spp., Strongyloides spp., Cyclospora sp. y Trichuris sp.

Conclusiones. Por lo menos, seis de los géneros de parásitos identificados tienen implicaciones zoonóticas, lo cual hace necesario establecer las posibles vías de infección de los primates del Zoológico de Cali e implementar protocolos de manejo que reduzcan el riesgo de transmisión a los humanos y a otros animales de la colección. Además, se presenta la información relevante sobre el potencial zoonótico de los enteroparásitos hallados.

Palabras clave: animales de zoológico; primates; parásitos; zoonosis; Cebidae; Callitrichidae.

Frequency of enteroparasites in Cebidae and Callitrichidae primates at the Zoológico de Cali, Colombia: Zoonotic implications

Introduction: Enteroparasites can cause problems in animals kept under human care in zoos and shelters. Wild animals have low parasitic loads but when sheltered in closed places they can be higher and lead to clinical manifestations, which increases the cost of medical treatments and care. On the other hand, some enteroparasites can represent a potential risk of zoonotic infection for their animal keepers, visitors, and other zoo animals. In addition, they could affect recovery programs for endangered species.

Objectives: To establish the presence and prevalence of potentially zoonotic enteroparasites in primates of the Cebidae and Callitrichidae families at the Zoológico de Cali from September to November, 2017.

Materials and methods: We conducted a prospective cross-sectional study. Serial samples from 50 individuals belonging to seven species and two primate families were analyzed by ova and parasite test, flotation, and Kinyoun stain between September and November, 2017. Results: In order of frequency, the parasite genera found in the seven primate species evaluated were Blastocystis spp., Trichomonas spp., Giardia spp., Entamoeba spp., Strongyloides spp., Cyclospora sp., and Trichuris sp.

Conclusions: At least six of the parasite genera found have potential zoonotic implications. It is necessary to establish what are the infection sources at the Zoológico de Cali and implement management protocols to reduce the risk of transmission to both humans and other animals in the collection. Additionally, we offer relevant information on the zoonotic potential of each of the enteroparasites found.

Keywords: Animals, zoo; primates; parasites; zoonoses; Cebidae; Callitrichidae. 
Los primates no humanos se encuentran amenazados por acciones como la reducción drástica de sus hábitats, la fragmentación de los bosques, la caza ilegal y el tráfico de fauna silvestre, lo que lleva a que cerca del $60 \%$ esté en peligro de extinción (1-5). Las especies neotropicales representan el $34 \%$ de las especies de primates del planeta (4).

Colombia ocupa el quinto lugar de diversidad de primates no humanos del Nuevo Mundo (2), pero varias especies endémicas están amenazadas (1). Para mitigar este impacto, el Zoológico de Cali participa en programas de educación ambiental, conservación y recuperación de especies amenazadas, y recibe animales mediante el intercambio con otros zoológicos o el rescate de manos de los traficantes de fauna silvestre por parte de las autoridades ambientales.

Es frecuente encontrar una alta prevalencia de parásitos y comensales intestinales que causan morbilidad y mortalidad en los primates bajo cuidado humano $(6,7)$. Los parásitos intestinales más comúnmente reportados son organismos unicelulares, hongos, nematodos, platelmintos y acantocéfalos, y es común que los animales tengan dos o más especies simultáneamente. Las prevalencias de algunos de ellos llegan a más del $35 \%$ y varían en el tiempo debido a factores bióticos y abióticos (8-12).

El parasitismo intestinal en los primates no humanos puede causar síntomas como diarrea, cólicos, vómitos, prolapso rectal, fiebre, daño mecánico, malabsorción de nutrientes, pérdida de electrolitos y, en casos graves, obstrucción intestinal, lo que provoca la pérdida de su condición corporal y cambios de comportamiento que indican que su enfermedad cursa de manera grave y que, incluso, puede llevarlos a la muerte (9) y afectar los programas de recuperación de especies en peligro.

Algunas especies de Cryptosporidium presentes en animales bajo cuidado humano (11) pueden ocasionar infecciones intestinales y extraintestinales en niños e individuos inmunocomprometidos $(12,13)$. Entamoeba histolytica en primates y humanos y E. nuttalli en primates se consideran extremadamente patógenas y causan infecciones extraintestinales que pueden ser mortales (14-16). Strongyloides spp. se ha informado como una causa importante de morbilidad en animales bajo cuidado humano, lo que incrementa los gastos de atención médica (17), en tanto que Blastocystis spp. y Giardia spp. son frecuentes en animales silvestres y en aquellos bajo cuidado humano, incluidos los primates no humanos, así como en el hombre, lo cual revela su potencial zoonótico (18-23).

En este estudio, se determinaron la presencia y la prevalencia de enteroparásitos con potencial de transmisión zoonótica en primates de las familias Cebidae (Cebus capucinus, Sapajus apella y Saimiri sciureus) y Callitrichidae (Cebuella pygmaea, Saguinus leucopus, S. oedipus y S. fuscicollis) del Zoológico de Cali, entre septiembre y noviembre de 2017.

\section{Materiales y métodos}

El estudio, de tipo transversal prospectivo, se llevó a cabo en el Zoológico de Cali, entre septiembre y noviembre del 2017. El zoológico está situado en el bosque municipal, a orillas del río Cali, en la ciudad de Santiago de Cali (Valle del Cauca, Colombia), a una altura de 1.000 m.s.n.m. y con una precipitación anual promedio de $1.483 \mathrm{~mm}$. Alberga alrededor de 2.500 animales, el $21 \%$ de ellos mamíferos. Las dos familias de primates tenían 50 individuos distribuidos en 19 recintos con uno a nueve individuos cada uno. 
En total, fueron 32 hembras (64\%), 13 machos (26\%) y cinco individuos sin sexo determinado (10\%).

Los cuidadores recolectaron en tres ocasiones las muestras de materia fecal de cada recinto, con intervalos inferiores a dos semanas entre recolecciones, empleando una técnica aséptica, guantes y recipientes limpios en cada ocasión. En los recintos ocupados por grupos no era posible realizar el muestreo de forma individual, por lo que se tomaron hasta cuatro muestras frescas simultáneas que se consideraron representativas del total de los animales de esa unidad de muestreo (17). Las muestras se recogían de aquellas deposiciones que estuvieran sobre el piso de concreto del recinto, evitando las que estaban sobre la tierra o el césped.

Los recipientes se rotularon adecuadamente y se llevaron al laboratorio del zoológico antes de una hora al cabo de la recolección. Se procesaron para la detección de enteroparásitos por examen coprológico directo (solución salina y lugol), concentración por flotación con sulfato de cinc y tinción ácido-alcohol resistente (Kinyoun) y se observaron con objetivos de 10X, 40X y 100X, según la técnica (24). La identificación se hizo con base en las características morfológicas de los microorganismos.

Los resultados se ingresaron en una base de datos en Excel, y se determinaron frecuencias y medidas de tendencia central. Con el paquete IBM SPSS ${ }^{\text {TM }}$, statistics (versión 23), se estudió si había asociación o independencia entre las variables "familia de primate" e "infección" en cada una de las parasitosis encontradas, empleando la prueba exacta de Fisher con un nivel de significación estadística establecido $(\alpha)$ de 0,05 .

\section{Aspectos éticos}

El estudio fue aprobado por el Comité Institucional de Revisión Ética con Animales en Experimentación de la Universidad del Valle mediante el Acta No. 001-017 del 31 de mayo de 2016, y por la Fundación Zoológico de Cali.

\section{Resultados}

Se tomaron muestras seriadas completas en 16 recintos, todos positivos para parasitismo intestinal en el momento del estudio y se descartaron tres recintos en los cuales se hospedaban diez animales, ya que en ellos no fue posible tomar la totalidad de las muestras del seriado. Así, el grupo evaluado quedó conformado por 40 individuos y el $100 \%$ presentó una entidad parasitaria, por lo menos.

En cuanto a la riqueza parasitaria por especie de primate, Saguinus leucopus (Callitrichidae) fue la que presentó la mayor variedad de parásitos (dos nematodos Trichuris sp. y un adulto sin identificar, y seis protozoos de Giardia spp., Cyclospora spp., Blastocystis spp., Trichomonas spp., Entamoeba spp., y uno sin identificar). Le siguieron Saimiri sciureus (Cebidae), con cuatro parásitos (Blastocystis spp., Trichomonas spp., Entamoeba spp. y Strongyloides spp.), Sag. oedipus, con tres (Giardia spp., Blastocystis spp. y Trichomonas spp.) y Cebuella pygmaea (Callitrichidae), con tres (Blastocystis spp., Trichomonas spp. y Entamoeba spp.). Por último, los cébidos Cebus capucinus (Blastocystis spp.) y Sapajus apella (Giardia spp.), y el calitrícido Sag. fuscicollis (Blastocystis spp.), presentaron un tipo de enteroparásito.

En el análisis etario, la mayor prevalencia de infección se presentó en los animales mayores de 11 años, seguidos de los menores de un año y los 
de 13 meses a 5 años (cuadro 1). El microorganismo de mayor frecuencia según el número de individuos parasitados fue Blastocystis spp., seguido por Trichomonas spp., Giardia spp., Entamoeba spp. (E. histolytica/E. dispar/E. moskovskii/E. nuttalli), Strongyloides spp., Cyclospora sp. y Trichuris sp. Por otro lado, en el análisis por recintos, los parásitos o comensales intestinales más prevalentes fueron Blastocystis spp., Trichomonas spp., Entamoeba spp. (E. histolytica/E. dispar/E. moskovskii/E. nuttalli) y Giardia spp. Los de menor frecuencia fueron Strongyloides spp., Trichuris sp. y Cyclospora sp. (cuadro 2).

En las 22 hembras, los 13 machos y los 5 individuos de sexo indeterminado, se identificaron agentes parasitarios o comensales. Al analizar el número de recintos y la cantidad de especies parasitarias en cada uno de ellos, así como el número de especies parasitarias en las dos familias de primates, se pudo apreciar que el monoparasitismo era la condición más frecuente tanto en los recintos como por familia, seguido por el poliparasitismo de dos y tres especies, y con menor frecuencia, el poliparasitismo de cuatro especies. En los cuadros 3 y 4 se pueden apreciar las asociaciones entre las diferentes especies de parásitos en los individuos con infecciones múltiples por familia y por recinto.

Cuadro 1. Distribución etaria de primates Cebidae y Calitrichidae analizados y total de individuos parasitados

\begin{tabular}{llcl}
\hline Edad & $\mathbf{n}$ & Total de individuos & $\%$ \\
\hline 0-12 meses & 4 & 5 & 80 \\
13 meses a 5 años & 8 & 10 & 80 \\
6-10 años & 9 & 13 & 69,2 \\
211 años & 8 & 9 & 88,8 \\
Indeterminada & 2 & 3 & 66,7 \\
\hline
\end{tabular}

Cuadro 2. Prevalencia de parásitos en primates Cebidae y Calitrichidae por número de individuos infectados y su distribución por recintos en valores absolutos y porcentajes

\begin{tabular}{lcc}
\hline Parásito & $\begin{array}{c}\text { Parásitos o comensales } \\
\text { por número de } \\
\text { individuos } \mathbf{( N = 4 0 )}\end{array}$ & $\begin{array}{c}\text { Parásitos o comensales } \\
\mathbf{n}(\%)\end{array}$ \\
$\begin{array}{lcc}\text { por recintos (N=16) } \\
\mathbf{n}(\%)\end{array}$ \\
\hline Blastocystis spp. & $30(75)$ & $14(84,2)$ \\
Trichomonas spp. & $11(27,5)$ & $5(31,3)$ \\
Giardia spp. & $11(27,5)$ & $3(18,8)$ \\
Entamoeba spp. (Entamoeba & $10(25)$ & $4(25)$ \\
histolytica/E. dispar/E. & & \\
moskovskii/E. nuttalli) & $6(15)$ & $1 \quad(6,3)$ \\
Strongyloides spp. & $2(5)$ & $1 \quad(6,3)$ \\
Cyclospora sp. & $1(2,5)$ & $1 \quad(6,3)$ \\
Trichuris sp. & &
\end{tabular}

Cuadro 3. Prevalencia de parasitismo en primates Cebidae y Calitrichidae por sexo y número de individuos, en valores absolutos y porcentajes

\begin{tabular}{lclrr}
\hline Análisis por sexo & & & & \\
\hline Sexo & $\begin{array}{c}\text { Animales por sexo } \\
\mathbf{n}\end{array}$ & \multicolumn{1}{c}{ Tipo de parasitismo } & $\mathbf{n}$ & $\%$ \\
\hline Hembras & 22 & Monoparasitismo & 14 & 63,6 \\
& & Poliparasitismo, 2 especies & 2 & 9,1 \\
& & Poliparasitismo, 3 especies & 2 & 9,1 \\
& & Poliparasitismo, 4 especies & 4 & 18,2 \\
\hline Machos & 13 & Monoparasitismo & 5 & 38,5 \\
& & Poliparasitismo, 2 especies & 6 & 46,2 \\
& & Poliparasitismo, 3 especies & 1 & 7,7 \\
& & Poliparasitismo, 4 especies & 1 & 7.7 \\
\hline Indeterminado & 5 & Monoparasitismo & 5 & 100 \\
\hline
\end{tabular}


Cuadro 4. Asociación de especies en individuos con poliparasitismo y su distribución por recintos

\begin{tabular}{|c|c|c|c|c|}
\hline Tipo de infección & $\begin{array}{c}\text { Total de recintos } \\
\text { afectados }(\mathrm{N}=16) \\
\mathrm{n} \\
\end{array}$ & $\begin{array}{c}\text { Número de recintos por } \\
\text { tipo de parasitismo } \\
n\end{array}$ & Parásitos & $\%$ \\
\hline \multirow[t]{2}{*}{ Monoparasitismo } & 7 & 6 & Blastocystis spp. & 42,8 \\
\hline & & 1 & Giardia spp. & \\
\hline \multirow[t]{2}{*}{$\begin{array}{l}\text { Poliparasitismo, } 2 \\
\text { especies }\end{array}$} & 4 & 2 & $\begin{array}{l}\text { Blastocystis spp. } \\
\text { Trichomonas spp. }\end{array}$ & 25 \\
\hline & & 2 & $\begin{array}{l}\text { Blastocystis spp. } \\
\text { Entamoeba spp. }\end{array}$ & \\
\hline \multirow[t]{4}{*}{$\begin{array}{l}\text { Poliparasitismo, } 3 \\
\text { especies }\end{array}$} & 4 & 1 & $\begin{array}{l}\text { Trichuris sp. } \\
\text { Giardia spp. } \\
\text { Trichomonas spp. }\end{array}$ & 25 \\
\hline & & 1 & $\begin{array}{l}\text { Blastocystis spp. } \\
\text { Cyclospora spp. } \\
\text { Protozoo sin identificar }\end{array}$ & \\
\hline & & 1 & $\begin{array}{l}\text { Blastocystis spp. } \\
\text { Entamoeba spp. } \\
\text { Nematodo adulto sin identificar }\end{array}$ & \\
\hline & & 1 & $\begin{array}{l}\text { Blastocystis spp. } \\
\text { Trichomonas spp. } \\
\text { Giardia spp. }\end{array}$ & \\
\hline $\begin{array}{l}\text { Poliparasitismo, } 4 \\
\text { especies }\end{array}$ & 1 & 1 & $\begin{array}{l}\text { Blastocystis spp. } \\
\text { Entamoeba spp. } \\
\text { Strongyloides spp. } \\
\text { Trichomonas spp. }\end{array}$ & 6,2 \\
\hline
\end{tabular}

Al comparar los parásitos según la cantidad de especies huéspedes que pueden infectar, Blastocystis spp. se encontró en un mayor número de especies de primates, con seis distintas especies de huéspedes en las dos familias de primates no humanos del Nuevo Mundo. Trichomonas spp. se encontró en cuatro especies de primates, en tanto que Giardia spp. y Entamoeba spp. se encontraron en tres huéspedes cada una y, Trichuris sp., Cyclospora sp. y Strongyloides spp., solo en una especie cada una (cuadro 5). Al comparar la cantidad de especies parasitarias encontradas en cada especie de primate, Sag. leucopus $(\mathrm{n}=8)$ presentó seis distintos parásitos (Trichuris sp., Giardia spp., Cyclospora sp., Blastocystis spp., Trichomonas spp. y Entamoeba spp.), siendo los de mayor diversidad de microorganismos, mientras que la menor variedad de parásitos ocurrió en Sag. fuscicollis $(n=1)$, C. capucinus $(n=6)$ y Sap. apella $(n=9)$, con una especie de parásito cada uno (Blastocystis spp. en las dos primeras especies y Giardia spp. en la otra) (figura 1 y cuadro 5).

En los recintos en los que se obtuvieron las tres muestras seriadas, mediante el primer examen se diagnosticaron infecciones parasitarias en siete $(43,8 \%)$, en tanto que los otros nueve recintos fueron negativos. De estos últimos, ocho fueron positivos en la segunda muestra. El acumulado de positivos para las dos primeras muestras fue del 93,8 \%. En el recinto que albergaba al grupo de individuos de Sap. apella, las dos primeras muestras fueron negativas y, en la tercera, el resultado fue positivo para Giardia spp. (cuadro 6). De los tres recintos en los que solo se recolectó una muestra, dos fueron positivos para Blastocystis spp. y el otro fue negativo.

En la prueba exacta de Fisher, tomando como muestra el número de recintos, $(n=16)$, se encontró que las variables "familia de primate" y cada una de las parasitosis encontradas no tenían asociación estadísticamente significativa, es decir, eran independientes. 
Cuadro 5. Número de individuos positivos Vs. número total de individuos por parásito para las diferentes especies de las familias Cebidae y Callitrichidae del Zoológico de Cali

\begin{tabular}{lccccccc}
\hline Especie & $\begin{array}{c}\text { Blastocystis } \\
\text { spp. }\end{array}$ & $\begin{array}{c}\text { Trichomonas } \\
\text { spp. }\end{array}$ & spp. & spp. & Strongyloides & Cyclospora & Trichuris \\
spp. & sp. & sp. \\
\hline Callitrichidae & & & & & & & \\
Saguinus leucopus & $7(8)$ & $3(8)$ & $1(8)$ & $2(8)$ & $0(8)$ & $2(8)$ & $1(8)$ \\
Saguinus fuscicollis & $1(1)$ & $0(1)$ & $0(1)$ & $0(1)$ & $0(1)$ & $0(1)$ & $0(1)$ \\
Saguinus oedipus & $4(4)$ & $1(4)$ & $0(4)$ & $2(4)$ & $0(4)$ & $0(4)$ & $0(4)$ \\
Cebidae & & & & & & & \\
Cebuella pygmaea* & $6(6)$ & $1(6)$ & $1(6)$ & $0(6)$ & $0(6)$ & $0(6)$ & $0(6)$ \\
Cebus capucinus & $6(6)$ & $0(6)$ & $0(6)$ & $0(6)$ & $0(6)$ & $0(6)$ & $0(6)$ \\
Sapajus apella & $0(9)$ & $0(9)$ & $9(9)$ & $0(9)$ & $0(9)$ & $0(9)$ & $0(9)$ \\
Saimiri sciureus & $6(6)$ & $6(6)$ & $0(6)$ & $6(6)$ & $6(6)$ & $0(6)$ & $0(6)$ \\
Total & $30(40)$ & $11(40)$ & $11(40)$ & $10(40)$ & $6(40)$ & $2(40)$ & $1(40)$ \\
\hline
\end{tabular}

El número en paréntesis corresponde al total de individuos de la especie.

${ }^{*}$ No se incluyeron los primates sin el seriado completo.

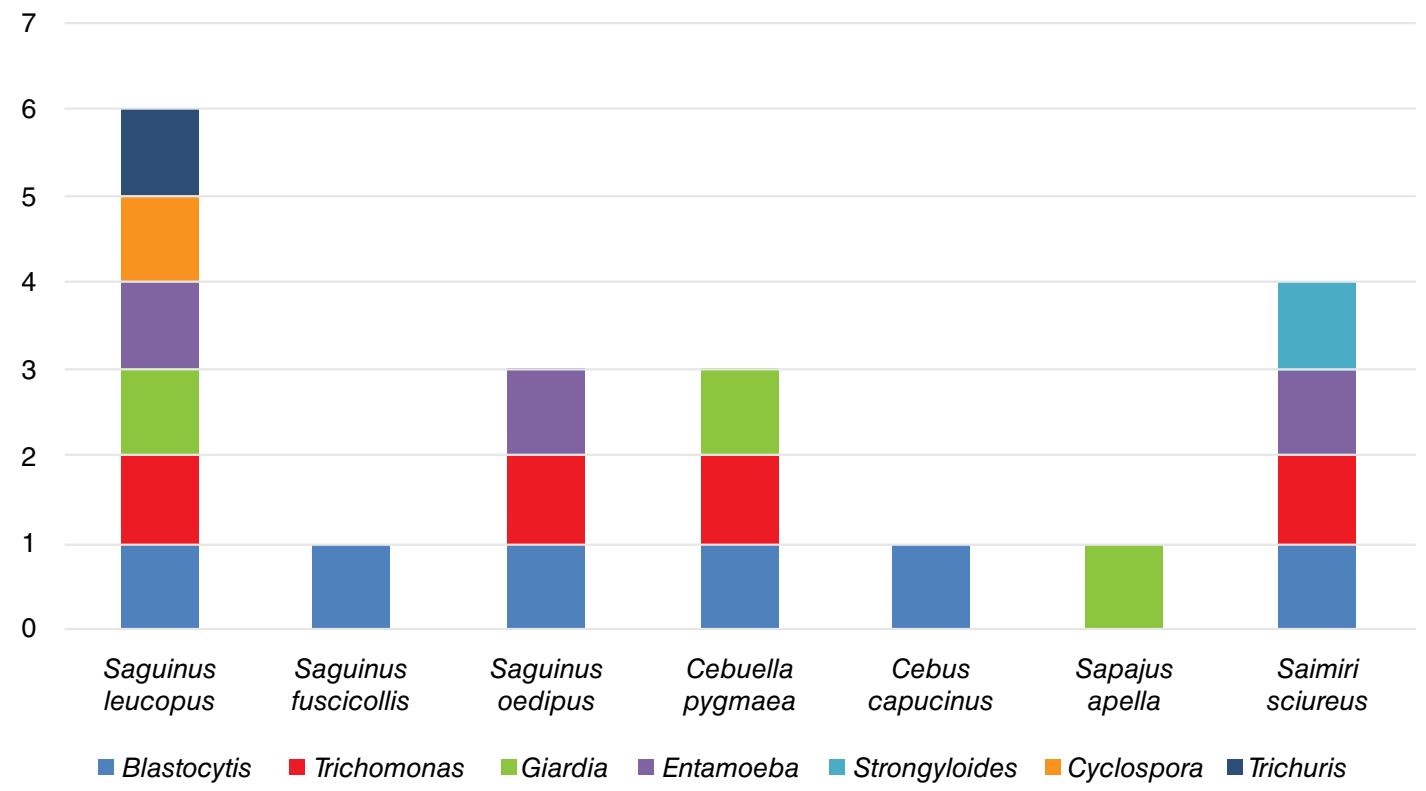

Figura 1. Diversidad de enteroparásitos (riqueza de especies parásitas) en los primates de las familias Cebidae y Callitrichidae en el Zoológico de Cali (Blastocystis spp., Trichomonas spp., Giardia spp., Entamoeba spp., Strongyloides spp., Cyclospora sp. y Trichuris sp.)

Cuadro 6. Muestras de materia fecal positivas en las distintas tomas del examen seriado (datos por recinto)

\begin{tabular}{lcrr}
\hline $\begin{array}{l}\text { Muestra en la cual se } \\
\text { detectaron los parásitos }\end{array}$ & $\begin{array}{c}\text { Número de recintos positivos } \\
(\mathbf{N}=\mathbf{1 6})^{*}\end{array}$ & $\%$ & $\begin{array}{c}\% \\
\text { acumulado }\end{array}$ \\
\hline 1 & $\mathbf{n}$ & & \\
2 & 7 & 43,8 & 43,8 \\
3 & 8 & 50,0 & 93,8 \\
\hline
\end{tabular}

* De los 19 recintos hubo tres en donde solo se obtuvo una muestra.

\section{Discusión}

En el presente estudio se determinó la presencia y la prevalencia de enteroparásitos con potencial de transmisión zoonótica en primates de las familias Cebidae y Callitrichidae del Zoológico de Cali. En aquellos espacios con 
más de un individuo, se consideró que el riesgo de exposición era similar para todos y que los resultados eran aplicables a todos los primates del recinto (17). La frecuencia de infección parasitaria en las especies de primates evaluadas fue del $100 \%$, similar a lo reportado en otros zoológicos en Perú (7) y Colombia (25), ambas mayores del $95 \%$, pero mayor que la reportada en otros zoológicos de Bélgica (17), China (18), Medellín (26), España (27) y Costa Rica (28), así como en estudios con animales silvestres libres en Costa Rica (29), Perú (30) y Colombia (31), todos con frecuencias entre el 25 y el $75 \%$.

Cabe destacar el estudio de Fajardo, et al., realizado también en el Zoológico de Cali, en el cual se encontró una prevalencia de parasitismo mucho menor de Entamoeba spp. y uncinarias en C. capucinus $(6,35 \%$ cada uno), en tanto que no se encontró parasitismo en los ejemplares de Sag. leucopus (32). Es importante mencionar que, en algunos de los trabajos referenciados, se utilizó una única toma de muestra $(1,7,25,30)$, lo que permite pensar que la sensibilidad en el diagnóstico de las infecciones con bajas cargas parasitarias fue menor, mientras que, en este trabajo, se evaluaron muestras seriales para todos los recintos, con el fin de mejorar la sensibilidad del examen directo y de la coloración.

Debe señalarse que los animales que el Zoológico de Cali recibe por intercambio o decomiso entran en cuarentena en un área independiente, durante la cual se les hacen diversas evaluaciones clínicas periódicas para establecer su estado de salud, incluidos exámenes sanguíneos y estudios seriados de materia fecal. Pasado este periodo, se aplica el protocolo para su introducción como individuos fundadores y no se los introduce en grupos ya establecidos para, así, garantizar la inocuidad de los nuevos individuos que se integran a la colección del Zoológico.

Como los parásitos detectados en los primates evaluados en este estudio son transmitidos principalmente por agua y alimentos, con excepción de Strongyloides spp., que penetra por la piel, es importante señalar que el Zoológico cuenta con su propia planta de potabilización de agua con cloro para el suministro a los diversos recintos; sin embargo, hay que tener en cuenta que varias especies de enteroparásitos presentan estructuras resistentes a la cloración del agua, por lo que para algunos animales especialmente propensos se ha establecido un protocolo de potabilización por ósmosis inversa que reduce el riesgo de infección por Toxoplasma gondii (33). Con respecto a las frutas y verduras que se emplean para la alimentación de los primates, estas se manejan con protocolos similares a los establecidos para la manipulación de los alimentos para consumo humano y son suministrados en bandejas plásticas que se lavan después de cada uso.

Por otra parte, el protocolo de manejo de enteroparásitos en el Zoológico de Cali implica la evaluación de cada recinto tres veces al año mediante examen coprológico directo y concentración. Cuando se encuentran individuos positivos, se establece el tratamiento y se evalúa la necesidad de tratar los recintos adjuntos; si hay individuos sintomáticos, por ejemplo, por diarrea, se hace el diagnóstico, se da tratamiento grupal y, solo en condiciones especiales, dadas las implicaciones sociales, se aísla al individuo para su manejo en la clínica bajo observación continua.

Los recintos de los primates en el Zoológico de Cali cuentan con una zona de manejo con superficies lavables, así como zonas con hierba para simular condiciones naturales. Debido a la dificultad de su lavado, estas zonas pueden actuar como reservorio para las formas infectivas de los parásitos 
gastrointestinales, lo que facilita su permanencia y viabilidad en el tiempo, y la reinfección de los individuos, y explicaría las altas tasas de prevalencia halladas en este y otros estudios $(3,17,21)$. Por otra parte, es difícil controlar el ingreso de animales, como pequeñas aves, roedores e insectos (cucarachas y moscas) a los recintos; estos animales pueden volverse parte de la dieta de los primates bajo cuidado humano y los convierte en un factor de riesgo de infección parasitaria $(34,35)$.

La prevalencia general de helmintos en las dos familias de primates fue baja comparada con otros estudios, lo que se explicaría por las bajas cargas parasitarias de los individuos y porque el examen directo no es la mejor técnica para el diagnóstico de las infecciones por Strongyloides spp. Asimismo, podría tener relación con la propensión de los huéspedes a la infección, o con su comportamiento, y con los protocolos de manejo implementados en el zoológico $(31,36)$. En estudios de cébidos en vida silvestre en Costa Rica $(37,38)$ y Colombia $(1,31)$, los parásitos de mayor frecuencia fueron helmintos, incluidos acantocéfalos, y con menor frecuencia, los protozoarios, hecho que algunos autores explican como resultado de la dieta de algunos de estos primates, la cual puede incluir invertebrados que servirían de huéspedes intermediarios para algunos de estos helmintos $(31,37-39)$.

En cuanto a la frecuencia de monoparasitismo (43,8 \%) hallada en los cébidos y calitrícidos del Zoológico de Cali, esta fue similar a lo reportado en un estudio realizado en Costa Rica $(60,8 \%)(28)$, pero difiere de lo informado en estudios llevados a cabo en otros zoológicos $(17,40)$. La elevada frecuencia de monoparasitismo podría indicar también que, aunque las fuentes de infección son pocas, la simplicidad de los ciclos de vida de los parásitos detectados, monoxénicos, y el hecho de que sus estadios quísticos (Entamoeba spp., Blastocystis spp., Giardia spp.) son infectivos una vez son excretados por el huésped, facilitan que un animal se reinfecte después del tratamiento, ya que en algunos de los recintos es difícil limpiar totalmente la materia fecal. Ahora bien, si se compara el poliparasitismo en estos primates ( $25 \%$ como máximo) con el hallado en otros zoológicos, la frecuencia fue menor (41). Esto es importante porque las infecciones por múltiples especies parasitarias suelen causar cuadros clínicos más complicados en los individuos infectados y, por ende, aumentar los costos en tratamientos y cuidados.

El estrés causado por la permanencia en espacios restringidos y el contacto con seres humanos, se ha propuesto como una de las causas de la gran frecuencia de infecciones parasitarias intestinales en primates bajo cuidado humano. Se asocia con la reducción de la resistencia a las infecciones y el aumento de la cronicidad de estas parasitosis (42). Por ello, en el Zoológico de Cali se han intervenido los recintos siguiendo los protocolos establecidos en manuales de bienestar específicos para cada familia de primates (43-45), de manera que su diseño facilite un manejo y una interacción adecuados con el cuidador, y un mayor bienestar de los animales. Ello permitió que el Zoológico fuera certificado por la Association of Zoos and Aquariums (AZA) y la Asociación Latinoamericana de Parques Zoológicos y Acuarios (ALPZA). Además, se asigna un único cuidador para la alimentación y el aseo de los recintos para reducir el estrés en los animales a su cargo y el ingreso a las áreas de manejo se hace mediante motivación positiva, lo que se consigue con el diseño y la ambientación, y con estrategias de condicionamiento positivo como los premios. 
Por último, cabe resaltar la utilidad del examen seriado de materia fecal que, en este caso, permitió detectar más del $90 \%$ de los casos de infección en la segunda muestra evaluada, algo similar a lo reportado en otros estudios (28). En algunos de los primates no humanos del Nuevo Mundo, es frecuente que la muestra sea escasa o insuficiente para utilizar las técnicas rutinarias debido a la cantidad de materia fecal que expulsan, por lo cual la repetición de la toma de muestras múltiples en los recintos aumenta considerablemente la probabilidad de observar estadios parasitarios en el examen coprológico.

\section{Sobre el potencial zoonótico de los parásitos hallados en primates Cebidae y Callitrichidae}

Es importante resaltar el potencial zoonótico de algunos de los enteroparásitos encontrados en los primates del Zoológico de Cali, ya que podrían ser fuente de infección para sus cuidadores y para otros animales de la colección. En el caso de Blastocystis spp. y Trichomonas spp., no se ha definido claramente su papel en la enfermedad en animales $y$, a pesar de su elevada frecuencia en los primates evaluados, la mayoría estaban asintomáticos. Por su parte, Giardia spp. un protozoo frecuente en los animales del Zoológico de Cali, y es conocido su papel en la enfermedad animal y humana. En cuanto a Strongyloides spp., se presentó en pocos individuos de las dos familias de primates Cebidae y Callitrichidae; en el Zoológico se han presentado casos recurrentes de estrongiloidiasis crónica en lémures, que podrían ser un foco de infección para humanos.

Entre los enteroparásitos unicelulares, Blastocystis spp. es uno de los más frecuentemente hallados en muestras fecales de personas sintomáticas y asintomáticas $(23,46)$. Sin embargo, todavía se debate su papel patogénico, aunque se han descrito casos de enfermedad diarreica y otros trastornos gastrointestinales y extraintestinales en personas en las que no se encuentra otro agente patógeno, incluidos el síndrome de colon irritable y la enfermedad inflamatoria del colon (46-49). A pesar de la elevada prevalencia en los animales del Zoológico de Cali y en otros, estos usualmente no presentan sintomatología, por lo que se sugiere que no es agente patógeno para los animales (48). Se han descrito 17 subtipos de Blastocystis spp. en diferentes huéspedes vertebrados, incluidos varios primates, y en el hombre (23,49-51) se han aislado 10 subtipos (ST1-ST9 y ST12) (52). Blastocystis spp. fue el parásito de mayor prevalencia en las dos familias de primates en este estudio $(84,2 \%)$, similar a lo reportado en otras investigaciones $(23,49,50,53)$. También, se ha reportado en cébidos y calitrícidos en zoológicos y reservas naturales de Perú, Chile y Colombia (26,30,54-57). En los estudios en Colombia con técnicas moleculares, se halló una baja prevalencia de Blastocystis spp. en primates silvestres del Magdalena Medio (31), lo que indicaría que el estar bajo cuidado humano los expone a este organismo, en tanto que, en condiciones silvestres, tiene menor relevancia este parásito.

Se han llevado cabo algunos estudios de caracterización genética de Blastocystis spp., principalmente a partir de aislamientos provenientes de primates del Viejo Mundo $(23,30,53,58,59)$. En algunos zoológicos europeos, se determinó que los ejemplares de la familia Callitrichidae (Saguinus labiatus y Callithrix jacchus) presentaban los subtipos 1 y 3 , dos de los más frecuentes en humanos, mientras que los del Viejo Mundo presentaron los subtipos 1, 2, 3, 5 y 8 , entre otros, y con prevalencias mayores que las observadas en los del Nuevo Mundo (58-61). 
Aunque humanos y primates comparten diferentes subtipos, hay variación en la frecuencia de los patrones de alelos entre ellos en los humanos, predomina el alelo 4 del subtipo $1 \mathrm{y}$, en los primates, se encuentran seis alelos distintos, más frecuentes que el 1 y el 2 . Al igual que en otras investigaciones $(22,58,61)$, en un par de muestras de cuidadores de los zoológicos evaluados en uno de los estudios, se encontraron alelos que coincidieron con los observados en primates (alelos 2 y 6), lo que demuestra que puede haber transmisión zoonótica entre los animales y sus cuidadores. Esta situación es similar a la observada con el subtipo 3 y sus alelos, los cuales difieren entre humanos y primates, aunque en los primates ninguno de los alelos presenta una frecuencia dominante, lo que refleja que no hay una especificidad por estos huéspedes (60).

En otros estudios se ha demostrado la posible transmisión zoonótica de los subtipos 1, 2 y 8; este último es bastante raro en humanos, excepto en cuidadores de zoológicos $(22,60,62)$. Aunque se comparten los subtipos, hay diferencias en los alelos entre los aislamientos de Blastocystis spp. de primates bajo cuidado humano y los de humanos. Sin embargo, no se ha determinado cuáles son los alelos circulantes en poblaciones silvestres y si también se presentan en humanos.

La tricomoniasis intestinal es frecuente en los vertebrados terrestres del Zoológico de Cali (anfibios, reptiles, aves y mamíferos) y se diagnostica rutinariamente en los controles periódicos de todos los animales de la colección en los que participan dos de los autores de este trabajo; sin embargo, parece ser de poca relevancia en los primates, aunque se han detectado individuos parasitados en vida silvestre y bajo cuidado humano. En Costa Rica se informó su presencia hasta en el $11 \%$ de un grupo de cébidos silvestres ( $C$. capucinus) (29) y, en el presente estudio, la frecuencia fue mayor, de $31 \%$.

Aunque en el momento del estudio ninguno de los animales infectados presentó alteraciones gastrointestinales, en el 2015 hubo en el Zoológico de Cali un caso fatal de tricomoniasis intestinal en un lémur (Varecia variegata) con diarrea crónica y linfangiectasia. Este individuo presentó una infección persistente con elevada carga parasitaria y fue tratado por uno de los autores sin lograrse la curación completa por resistencia al tratamiento con metronidazol. Por otra parte, en un primate del Nuevo Mundo de la familia Pithecidae (Callicebus moloch), se reportó un caso de tricomoniasis invasiva que se manifestó con depresión, diarrea y deshidratación. La histolopatología reveló la presencia de abundantes trofozoítos en diversas áreas del colon y en los ganglios linfáticos mesentéricos; el parásito se identificó mediante microscopía electrónica, sin evidencia de otro agente patógeno (63).

Actualmente, se aceptan nueve especies de Trichomonas diferenciadas principalmente por su morfología, muchas de ellas descritas en primates del Viejo y el Nuevo Mundo en un único reporte (64); entre ellas, está Tritrichomonas mobilensis, descrita en Saimiri boliviensis boliviensis, un primate del Nuevo Mundo (65). En uno de los estudios en que se han utilizado técnicas moleculares para determinar cuántas especies de Trichomonas intestinales infectan distintos huéspedes, se estudiaron 10 especies de primates del Viejo Mundo y un calitrícido ( $C$. jacchus); 25 aislamientos de dichos primates (Hylobates syndactylus, Pantroglodytes, Lemur catta, Macaca silenus, M. nigra, Mandrillus sphinx y Semnopithecus entellus) se agrupaban en varios grupos o linajes del género Tetratrichomonas, y los autores propusieron separarlos, por lo 
menos, en ocho especies (64). En este mismo grupo, se alineó un flagelado aislado de un paciente humano con empiema pleural (66), en tanto que un aislamiento de $L$. catta se asoció con $T$. gallinarum, especie que se ha aislado de la cavidad oral, los bronquios y el esputo de seres humanos (67). Un aislamiento de Otolemur garnettii se asoció con Hypotrichomonas acosta, un flagelado encontrado en serpientes, y otro de $L$. catta se relacionó estrechamente con Trichomitus batrachorum, un género de anfibios y reptiles emparentado con Hypotrichomonas en Hypotrichomonadea (Parabasalia).

Por último, la secuencia de tres aislamientos de Colobus angolensis, $V$. variegata y $C$. jacchus fue muy similar a la reportada para Pentatrichomonas hominis en ganado y humanos (64). Estos hallazgos revelan-que la diversidad de parabasálidos en primates es mayor de la estimada y plantea la necesidad de estandarizar las técnicas moleculares para la correcta identificación de los trichomonadidos intestinales presentes en primates bajo cuidado humano, ya que pueden tener potencial zoonótico, como se ha demostrado con Tetratrichomonas y P. hominis; esta última puede causar enfermedad bajo ciertas condiciones en animales silvestres bajo cuidado humano, en humanos y en animales domésticos (Núñez J, Zerpa R, Lucas CM, Lugo-Román LA, Gregory MJ, Maves RC, et al. Pentatrichomonas hominis is associated with diarrheal episodes in captive-bred owl monkeys (Aotus nancymaae). 61st Annual Meeting. November 11-15, 2012. Atlanta, GA, USA: American Society of Tropical Medicine and Hygiene; 2012) (68-73). Es necesario caracterizar genéticamente las cepas de Trichomonas spp. circulantes en el Zoológico de Cali para conocer las especies, y poder establecer si hay riesgo zoonótico y las medidas que minimicen la transmisión a otros animales de la colección y a los cuidadores.

La prevalencia de Entamoeba spp. (25\%) indica que es un parásito importante en los primates de las familias Cebidae y Callitrichidae del Zoológico de Cali. Otros estudios en zoológicos reportan prevalencias de $28,9,81,1$ y $100 \%(18,74,75)$.

En primates del Nuevo y el Viejo Mundo, se han descrito varias especies de este género, como Entamoeba histolytica, E. nuttali, E. chattoni (E. polecki de subtipo 2), E. polecki, E. hartmanni, E. coli, E. moshkovskii y E. dispar, de las cuales solo las dos primeras se han reportado como causantes de sintomatología intestinal y extraintestinal en algunos animales infectados $(16,19,41,74-77)$. Entre las especies de primates consideradas, solo se ha reportado E. chattoni (E. polecki de subtipo 2) en uno del Nuevo Mundo (Alouatta palliata, Atelidae) en Costa Rica (78), pero su descripción se basó en la comparación morfológica y morfométrica, y no en técnicas moleculares que lo confirmaran.

Con el empleo de zimodemos y PCR, se han detectado infecciones por $E$. nuttalli y E. chattoni (E. polecki de subtipo 2), mayoritariamente asintomáticas, en cuidadores de animales en zoológicos europeos $(15,41,79)$. De ahí la importancia de la determinación molecular de las especies de Entamoeba observadas en los animales analizados en este estudio ya que, de tratarse de E. nuttali o E. histolytica, pueden llegar a causar enfermedad clínica, ocasionalmente fatal. Asimismo, es necesario establecer los factores de riesgo asociados a las infecciones en estos animales, para reducir la transmisión tanto entre los primates como a otras especies del zoológico (79) o a sus cuidadores (15).

En humanos, G. duodenalis es uno de los principales protozoos causantes de diarrea, especialmente en niños (80). Actualmente, se han identificado 
ocho grupos $(\mathrm{A}-\mathrm{H})$ de esta especie, morfológicamente indistinguibles, pero genéticamente distintos, en diversos mamíferos (81), y algunos autores proponen separarlos como especies (82). Se ha visto que los grupos A y $\mathrm{B}$ de G. duodenalis tienen múltiples huéspedes y potencial zoonótico (83). Este protozoo se considera un agente patógeno importante en primates, en los que ocasiona diarrea y retraso en el crecimiento de animales jóvenes $(9,74,84,85)$.

En distintos países, los primates del Nuevo y el Viejo Mundo en condición silvestre o bajo cuidado humano en zoológicos, presentan estos parásitos, con prevalencias hasta del $94 \%(31,37,74,86-89)$. No obstante, son pocos los estudios moleculares de aislamientos provenientes de primates, destacándose los realizados en Italia y España en primates del Viejo Mundo, en los que se identificaron genotipos de Giardia spp. pertenecientes al grupo $B$, subgrupo BIV, también hallado en humanos $(74,88-90)$, lo que sugiere que pueden tener potencial zoonótico.

Sin embargo, se ha demostrado que la transmisión de Giardia spp. puede ser antroponótica o zoonótica bidireccional, de manera que los primates pueden ser reservorios para el humano, pero los seres humanos también inciden en la contaminación ambiental con quistes de Giardia spp. $(81,90)$. Hasta el momento no se han caracterizado genéticamente los aislamientos de Giardia spp. provenientes de primates en el Zoológico de Cali, por lo que se desconoce el verdadero riesgo zoonótico para los cuidadores y otros animales de la colección.

Trichuris trichiura es un nematodo que causa enfermedad en humanos y primates (91,92); se asume que solo esta especie infecta tanto a unos como a otros (93) y se reporta con frecuencia en primates no humanos del Nuevo y del Viejo Mundo en estado silvestre $(29,30,93-95)$ o bajo cuidado humano $(9,27,87,96,97)$, con prevalencias hasta del $100 \%$ en algunas especies del Viejo Mundo, y entre 1,94 y 11,64 \% en algunas del Nuevo Mundo bajo cuidado humano, incluidos cébidos y calitrícidos (8).

En S. fuscicollis (Callitrhricidae) silvestres de Colombia y Brasil, se han encontrado prevalencias del 50 y el $14 \%$, respectivamente, en tanto que, en Cebus versicolor (Cebidae) silvestres de Perú y Brasil, se ha informado una de $64,3 \%(29,30,96)$. En primates bajo cuidado humano en Colombia, $T$. trichiura se ha reportado en S. leucopus (54), y en Chile, en C. albifrons (57). En el Zoológico de Cali se detecta ocasionalmente en diversos mamíferos en coinfección con Capillaria sp., un helminto de aves.

En algunos estudios de caracterización de aislamientos de Trichuris sp. en primates no humanos del Viejo Mundo mediante diferentes marcadores moleculares, se detectó la presencia de $T$. trichiura $(98,99)$. En un reporte de Uganda en primates silvestres de áreas de contacto frecuente con humanos, se encontraron varios linajes de Trichuris sp. con elevada variabilidad genética y evidencia de que, al menos, uno de ellos era compartido por humanos y primates no humanos, lo que podría significar que tiene potencial zoonótico $(93,99)$.

En un estudio posterior, al analizar el genoma mitocondrial de aislamientos provenientes de humanos, cerdos y primates del Viejo Mundo bajo cuidado humano, se apreció una gran variabilidad y que los genotipos de primates y humanos formaban cinco y dos clados separados, respectivamente, distantes de los de cerdo. Se ha propuesto, entonces, que hay un complejo de especies crípticas que infectan a humanos y primates, y que algunas de ellas tienen 
gran especificidad de huéspedes, pero otras pueden infectar a unos y otros $(93,99)$. Aún se requieren estudios que permitan caracterizar genéticamente los parásitos encontrados en los primates no humanos del Nuevo Mundo para establecer si son especies distintas a T. trichiura y si tienen potencial zoonótico.

Otro parásito que se reporta con frecuencia en varios grupos de vertebrados, entre ellos los primates y el humano, es el nemátodo Strongyloides spp. (10,100-104). Hay tres especies descritas que infectan a los humanos; una es $S$. stercoralis, que se considera cosmopolita, y las otras dos presentan una distribución geográfica más restringida. S. fuelleborni fuelleborni causa zoonosis en primates y humanos de África y Asia, y $S$. fuelleborni kellyi infecta humanos de Papúa Nueva Guinea (104-106).

Strongyloides stercoralis puede cursar como una infección asintomática o causar cuadros clínicos complicados de hiperinfección o diseminación que pueden llegar a ser mortales, especialmente en animales jóvenes y en humanos inmunosuprimidos o con infección por el virus linfotrópico de células T humanas de tipo 1 (HTLV -1) (105-107). En el hemisferio occidental, solo se han informado dos casos humanos fatales de infección por S. fuelleborni, en Perú, en dos mujeres de 5 y 16 años, ambas positivas para infección con HTLV-1, que presentaron un cuadro diarreico, infección diseminada y sepsis bacteriana. El diagnóstico se basó en la identificación morfológica de los huevos en cadena con membrana envolvente y hembras adultas de vida libre con constricción posvulvar característica (106-108). Sin embargo, en Suramérica no se han descrito huéspedes naturales para S. fuelleborni.

Coincidente con los resultados del presente estudio, en primates no humanos del Viejo y del Nuevo Mundo bajo cuidado humano o silvestres, incluidos cébidos y calitrícidos de Colombia, Ecuador, Perú, Chile y Costa Rica, se han presentado infecciones por Strongyloides spp. Con frecuencias que fluctúan entre 1,94 y $66 \%(8,17,23,25,26,29,30,37,42,78,109-111)$. En cuanto a la infección en los del Nuevo Mundo, en algunos trabajos se ha reportado la presencia de S. cebus o Strongyloides sp. (42), pero sin que se hubieran empleado técnicas moleculares para establecer la especie involucrada en las infecciones detectadas. En Costa Rica se ha reportado en $C$. capucinus, $C$. albifrons y $C$. apella, silvestres y bajo cuidado humano, con prevalencias del 10 al $36 \%(29,37,38)$. En zoológicos de Chile y Perú, se ha informado en cébidos y calitrícidos (Saguinus mystax, S. fuscicollis, $S$. sciureus, C. apella y C. albifrons) $(30,39,42,57)$ y, en Colombia, en grupos de C. versicolor y S. leucopus de vida silvestre, con prevalencias entre 18,8 y $62,5 \%(1,31)$. Callithrix penicillata se ha empleado como un modelo biológico para evaluar la infección por S. stercoralis en individuos con inmunosupresión, lo que ha permitido observar que en estos primates la estrongiloidiasis se presenta con cuadros clínicos que van desde los no complicados hasta la condición grave, similar a lo que sucede en humanos (112), lo que demuestra que esta especie de primates es sensible a la infección por este nemátodo.

Debe tenerse en cuenta que la infección natural por S. stercoralis en primates silvestres del Viejo Mundo puede estar ligada al hecho de compartir su hábitat con humanos u otros animales que pueden portar el parásito, y además, que la infección puede llegar a causar una enfermedad fatal (113). Algunos estudios en estos primates, en los cuales se han empleado la caracterización y diferenciación molecular de S. stercoralis y S. f. fuellborni, han revelado la variabilidad genética de este parásito y su carácter zoonótico $(102,104,114)$. Una de las secuencias analizadas de S. f. kellyi es idéntica a 
una sequencia de S. cebus. La información obtenida con este gen y la de las secuencias SSU, permite separar dos clados, uno conformado por $S$. ratti, S. suis, S. venezuelensis, S. vituli y S. papillosus, y el otro basado en las secuencias de S. f. fuelleborni, que agrupa esta especie con secuencias idénticas de aislamientos de $S$. stercoralis a partir de humanos y perros, y de Strongyloides sp. de serpientes $(102,112,115)$.

Con base en estos hallazgos, se propone que S. f. kellyi puede ser una especie (Strongyloides kellyi) independiente de S. fuelleborni $(104,112)$. A pesar de que se ha demostrado que los humanos pueden estar infectados con diversos genotipos de $S$. stercoralis, y de que hay transmisión zoonótica de esta y otras especies, es necesario continuar estudiando a los primates no humanos del Nuevo Mundo para aclarar si las especies de Strongyloides presentes en ellos también se comportan de manera similar a las encontradas en los del Viejo Mundo.

Comparada con la reportada en algunos estudios, la prevalencia de Strongyloides spp. en el Zoológico de Cali fue baja, lo que puede estar asociado con los esquemas de tratamiento programados para los animales y su efectividad. Asimismo, podría estar relacionada con el subdiagnóstico de aquellos animales con cargas parasitarias bajas que no son detectados con métodos de poca sensibilidad como el examen coprológico directo, lo que hace necesario la implementación de técnicas que mejoren el diagnóstico, como el cultivo en agar o el embudo de Baermann o, idealmente, pruebas moleculares o dispositivos como el Flotac que no se emplearon en este estudio $(104,105,111,113,114)$.

En cuanto a la coccidia intestinal Cyclospora cayetanensis, se asocia con cuadros diarreicos en humanos, especialmente en países tropicales, donde afecta principalmente a niños y pacientes inmunosuprimidos, en tanto que. en los países desarrollados. se ha descrito principalmente en brotes por alimentos y como agente de diarrea del viajero (116). En primates no humanos, Cyclospora spp. se informa principalmente en los del Viejo Mundo, tanto silvestres como bajo cuidado humano en zoológicos, con prevalencias entre el 2,5 y el $68 \%$ (27,117-120).

Cyclospora cayetanensis (121) fue la primera especie descrita en primates humanos; posteriormente. se describieron tres nuevas especies ( $C$. cercopithecide, C. colobi y C. papionis) en Cercopithecus aethiops, Colobus guereza y Papio anubis en estado silvestre, respectivamente (122). El integrante más reciente de este grupo de parásitos intestinales de primates es C. macacae, aislada de Macaca mulatta (119). En Colombia y en México, se han reportado unos pocos casos de Cyclospora spp. en especies de primates silvestres del Nuevo Mundo de la familia Atelidae (Alouatta seniculus, $A$. pigra y Ateles geoffroyi) $(120,123)$. En ambos estudios la identificación se hizo mediante coloración ácido-alcohol resistente, pero no se hizo la caracterización molecular de los aislamientos. Hasta el momento, no se han reportado casos de transmisión de la infección por especies de Cyclospora de primates a humanos $y$, dado que este organismo está emparentado con Eimeria, es posible que tenga una gran especificidad de huéspedes, razón por la cual la infección cruzada sería muy rara $(40,122)$.

Con base en la información disponible sobre el potencial zoonótico de los distintos parásitos observados en estos primates del Zoológico de Cali, se recomienda implementar técnicas de laboratorio que permitan identificar estas especies crípticas para contribuir al conocimiento de la 
fauna parasitaria de los primates neotropicales y dar cuenta de la posible transmisión zoonótica en el parque. Queda por esclarecer si las diferencias entre familias y las infecciones por Blastocystis spp., más prevalente en calitrícidos, y por Giardia spp. y Strongyloides spp., más frecuentes en cébidos, son hallazgos incidentales, o si hay alguna característica genética, inmunológica o de exposición que las explique; además, si varían según los periodos lluviosos o secos, o se mantienen a lo largo del año.

Se identificaron siete géneros parasitarios en primates Cebidae y Callitrichidae del Zoológico de Cali, con una mayor prevalencia de Blastocystis spp., Giardia spp. y Trichomonas spp., teniendo los dos primeros un potencial zoonótico considerable. El presente estudio reveló que los protocolos de evaluación periódica y el tratamiento oportuno seguidos en el zoológico parecen ser efectivos para reducir las infecciones por helmintos, ya que estas se presentaron en menor proporción. Dado que el monoparasitismo fue más frecuente, la presencia de las infecciones por parásitos unicelulares debe conducir a la evaluación de posibles fuentes de infección (alimentos, agua, calzado de los cuidadores y animales recién llegados al zoológico), para diseñar estrategias que minimicen su efecto.

Estos resultados demuestran que es necesario implementar técnicas de diagnóstico molecular para conocer de manera precisa las especies y los genotipos presentes en los animales de la colección, y dilucidar las fuentes de transmisión y los riesgos de zoonosis. Además, son de utilidad para los protocolos de vigilancia y tratamiento, encaminados a controlar la transmisión y el riesgo de contaminación entre los animales y sus cuidadores. Después de este estudio, se introdujeron cambios en el manejo de algunos recintos, como el reemplazo total y periódico del pasto y la tierra, así como la desinfección con vapor de las instalaciones y el aseo del calzado de los cuidadores. Aún está pendiente evaluar la efectividad de estas estrategias en la reducción de la contaminación y la infección por enteroparásitos.

Se demostró que el análisis seriado de muestras para el diagnóstico de parásitos intestinales en animales bajo cuidado humano, es útil para minimizar el subdiagnóstico que se puede presentar con la toma de una única muestra. Por último, teniendo en cuenta que estas especies de primates están en riesgo, el conocimiento de los parásitos que los afectan permite elaborar esquemas de tratamiento y control que garanticen animales aptos para reproducirse y programas para introducirlos en ecosistemas silvestres.

\section{Agradecimientos}

Los autores agradecen al Zoológico de Cali y a la Universidad del Valle, por facilitar personal, equipos, reactivos e instalaciones sin los que no podría haberse llevado a cabo el estudio, y a los cuidadores de los animales del Zoológico de Cali, por su apoyo en la recolección de las muestras.

\section{Referencias}

1. Acevedo-Garcés YA, Álvarez-Cardona J, Vargas-Valencia V, Hernández-Castro C, GarcíaMontoya G, Soto-Calderón ID. Valoración clínica y parasitológica del tití gris (Primates: Cebidae: Saguinus leucopus) en dos poblaciones naturales presentes en San Carlos y San Rafael (Antioquia, Colombia). CES Med Vet Zootec. 2014;9:68-83.

2. Asociación Colombiana de Parques Zoológicos, Acuarios y Afines-ACOPAZOA. Studbook nacional y plan de manejo Tití gris (Saguinus leucopus- Günter 1876). Cuarta edición. Bogotá: ACOPAZOA; 2017. p. 89. Fecha de consulta: 20 de enero de 2020. Disponible en: http://www.acopazoa.org/sites/default/files/docs adjuntos/STUDBOOK\%20NACIONAL\%20 Y\%20PLAN\%20DE\%20MANEJO\%202017.pdf 
3. Bonell WY, Álvarez MA, Roncancio NJ. Population density of Saguinus leucopus (Mammalia: Primates) and landscape characteristics in eastern Antioquia, Colombia. Therya. 2018;9:618. https://doi.org/10.12933/therya-18-519

4. Estrada A, Garber PA, Rylands AB, Roos C, Fernández-Duque E, Di Fiore A. Impending extinction crisis of the world's primates: Why primates matter. Sci Adv. 2017;3:e1600946. https://doi.org/10.1126/sciadv.1600946

5. Corporación Autónoma Regional de Cundinamarca. Plan de manejo para las especies de primates presentes en las áreas de distribución potencial del tití gris Saguinus leucopus en jurisdicción de la CAR. Bogotá: CAR; 2012. Fecha de consulta: 12 de enero de 2020. Disponible en: https://www.car.gov.co/uploads/files/5bfc0d805d7a7.pdf

6. Li W, Deng L, Yu X, Zhong Z, Wang Q, Liu X, et al. Multilocus genotypes and broad hostrange of Enterocytozoon bieneusi in captive wildlife at zoological gardens in China. Parasit Vectors. 2016;9:395. https://doi.org/10.1186/s13071-016-1668-1

7. Mynářová $A$, Foitová I, Kváč $M$, Květoňová $D$, Rost $M$, Morrogh-Bernard $H$, et al. Prevalence of Cryptosporidium spp., Enterocytozoon bieneusi, Encephalitozoon spp. and Giardia intestinalis in wild, semi-wild and captive orangutans (Pongo abelii and Pongo pygmaeus) on Sumatra and Borneo, Indonesia. PLoS ONE. 2016;11:e0152771. https://doi.org/10.1371/journal.pone.0152771

8. Guerrero F, Serrano-Martínez E, Tantaleán M, Quispe-Marco, Casas G. Identificación de parásitos gastrointestinales en primates no humanos del zoológico parque natural de Pucallpa, Perú. Rev Inv Vet Perú. 2012;23:469-76. https://doi.org/10.15381/rivep.v23i4.962

9. Li M, Zhao B, Li B, Wang Q, Niu L, Deng J, et al. Prevalence of gastrointestinal parasites in captive non-human primates of twenty-four zoological gardens in China. J Med Primatol. 2015;44:168-73. https://doi.org/10.1111/jmp.12170

10. Fagiolini M, Lia RP, Laricchiuta P, Cavicchio P, Mannella R, Cafarchia C, et al. Gastrointestinal parasites in mammals of two Italian zoological gardens. J Zoo Wildl Med. 2010;41:662-70. https://doi.org/10.1638/2010-0049.1

11. Gracenea M, Gómez MS, Torres J, Carné E, Fernández-Morán J. Transmission dynamics of Cryptosporidium in primates and herbivores at the Barcelona zoo a long-term study. Vet Parasitol. 2002;104:19-26. https://doi.org/10.1016/S0304-4017(01)00611-2

12. Gu Y, Wang X, Zhou C, Li P, Xu Q, Zhao C, et al. Investigation on Cryptosporidium infections in wild animals in a zoo in Anhui province. J Zoo Wildl Med. 2016;47:846-54. https://doi.org/10.1638/2015-0301.1

13. Xiao LH, Fayer R. Molecular characterisation of species and genotypes of Cryptosporidium and Giardia and assessment of zoonotic transmission. Int J Parasitol. 2008;38:1239-55. https://doi.org/10.1016/j.jijpara.2008.03.006

14. Montenegro M, Sánchez-Negrette M, Lértora WJ. Diagnóstico histopatológico de entamoebiosis en un primate en cautiverio (Alouatta caraya). Rev Vet. 2010;21:59-62. https://doi.org/10.30972/vet.2111870

15. Levecke B, Dorny P, Vercammen F, Visser LG, van Esbroeck, Vercruysse J, et al. Transmission of Entamoeba nuttalli and Trichuris trichiura from nonhuman primates to humans. Emerg Infect Dis. 2015;21:1871-2. https://doi.org/10.3201/eid2110.141456

16. Tachibana H, Yanagi T, Akatsuka A, Kobayashi S, Kanbara H, Tsutsumi V. Isolation and characterization of a potentially virulent species Entamoeba nuttalli from captive Japanese macaques. Parasitology. 2009;136:1169-77. https://doi.org/10.1017/S0031182009990576

17. Levecke B, Dorny P, Geurden T, Vercammen F, Vercruysse J. Gastrointestinal protozoa in non-human primates of four zoological gardens in Belgium. Vet Parasitol. 2007;148:236-46. https://doi.org/10.1016/j.vetpar.2007.06.020

18. Li J, Qi M, Chang Y, Wang R, Li T, Dong H, et al. Molecular characterization of Cryptosporidium spp., Giardia duodenalis, and Enterocytozoon bieneusi in captive wildlife at Zheng Zhou Zoo, China. J Eukaryot Microbiol. 2015;62:833-9. https://doi.org/10.1111/jeu.12269

19. Farzan A, Parrington L, Coklin T, Cook A, Pintar K, Pollari F, et al. Detection and characterization of Giardia duodenalis and Cryptosporidium spp. on swine farms in Ontario, Canada. Foodborne Pathog Dis. 2011;8:1207-13. https://doi.org/10.1089/fpd.2011.0907

20. Milozzi C, Bruno G, Cundom E, Mudry MD, Navone GT. Intestinal parasites of Alouatta caraya (Primates, Ceboidea): Preliminary study in semi-captivity and in the wild in Argentina. Mastozool Neotrop. 2012;19:271-8. 
21. Matsubayashi M, Takami K, Kimata I, Nakanishi T, Tani H, Sasai K, et al. Survey of Cryptosporidium spp. and Giardia spp. infections in various animals at a zoo in Japan. J Zoo Wildl Med. 2005;36:331-5. https://doi.org/10.1638/04-032.1

22. Geurden T, Goossens E, Levecke B, Vercammen F, Vercruysse J, Claerebout E. Occurrence and molecular characterization of Cryptosporidium and Giardia in captive wild ruminants in Belgium. J Zoo Wildl Med. 2009;40:126-30. https://doi.org/10.1638/2008-0152.1

23. Parkar U, Traub RJ, Vitali S, Elliot A, Levecke B, Robertson I, et al. Molecular characterization of Blastocystis isolates from zoo animals and their animal-keepers. Vet Parasitol. 2010;169:8-17. https://doi.org/10.1016/j.vetpar.2009.12.032

24. Carvajal H, Caro FF, Bonelo A. El diagnóstico directo en parasitología. 1a edición. Cali: Editorial Universidad del Valle; 1995. p.14-6, 21-2.

25. Ortiz-Pineda MC, Pulido-Medellín MO, García-Corredor DJ. Identificación de parásitos gastrointestinales en mamíferos del Zoológico Guátika (Tibasosa, Colombia). Pensamiento y Acción. 2019;26:31-44.

26. Oyola N, Zapata-Salas R, Torres-Lindarte GA, Ríos-Osorio LA, Zapata-Tamayo MA. Frecuencia de parásitos intestinales en fauna exótica y silvestre del Zoológico Santa Fe en Medellín - Colombia. CES Medicina. 2010;24:108-9.

27. Pérez G, Hitos A, Romero D, Sánchez M, Pontes A, Osuna A, et al. Intestinal parasitism in the animals of the Zoological Garden "Peña Escrita" (Almuñecar, Spain). Vet Parasitol. 2008;156:302-9. https://doi.org/10.1016/j.vetpar.2008.05.023

28. Sibaja KD. Identificación de los parásitos gastrointestinales y ectoparásitos de animales silvestres en cautiverio en Costa Rica. Tesis. Costa Rica: Universidad Nacional de Costa Rica; 2006. Fecha de consulta: 6 de enero de 2020. Disponible en: https://www.repositorio. una.ac.cr/handle/11056/12913

29. Chinchilla M, Guerrero OM, Gutiérrez-Espeleta GA, Sánchez R, Valerio I. Parásitos en monos carablanca Cebus capucinus (Primates: Cebidae) de Costa Rica. Parasitol Latinoam. 2007;62:170-5. https://doi.org/10.4067/S0717-77122007000200011

30. Phillips KA, Haas ME, Brian WG, Yrivarren M. Survey of the gastrointestinal parasites of the primate community at Tambopata National Reserve, Peru. J Zool. 2004;264:149-51.

31. Rondón S, Ortiz M, León C, Galvis N, Link A, González C. Seasonality, richness and prevalence of intestinal parasites of three neotropical primates (Alouatta seniculus, Ateles hybridus and Cebus versicolor) in a fragmented forest in Colombia. Int J Parasitol Parasites Wildl. 2017;6:202-8. https://doi.org/10.1016/j.ijppaw.2017.07.006

32. Fajardo-Sánchez JE, Lasso-Narváez AM, Mera-Eraso CM, Peña-Stadlin J, Zapata-Valencia $\mathrm{JI}$, Rojas-Cruz C. Enteroparásitos con potencial zoonótico en animales en cautiverio del zoológico de Cali, Colombia. Neotrop Helminthol. 2014;8:279-90.

33. Catão-Dias JL, Epiphanio S, Kierulff MC. Neotropical primates and their susceptibility to Toxoplasma gondii: New insights for an old problem. In: Brinkworth J, Pechenkina K, editors. Primates, pathogens, and evolution. Developments in primatology: Progress and prospects. New York, NY: Springer; 2013. p. 253-89. https://doi.org/10.1007/978-1-4614-7181-3 9

34. Casana C, Chávez A, Abad-Amerí D, Pinedo R. Prevalence of Giardia spp. in rodents (Rattus spp.) of a zoo in Metropolitan Lima. Rev Inv Vet Perú. 2019;30:1207-15. https://doi.org/10.15381/rivep.v30i3.16606

35. Oyeyemi OT, Agbaje MO, Okelue UB. Food-borne human parasitic pathogens associated with household cockroaches and houseflies in Nigeria. Parasite Epidemiol Contr. 2016;1:103. https://doi.org/10.1016/j.parepi.2015.10.001

36. Montoya C, Oyola N, Ocampo M, Polanco D, Ríos S, Paola M, et al. Evaluación del parasitismo intestinal en monos aulladores rojos (Alouatta seniculus) en rehabilitación en el CAVR-Ecosantafé, Jericó, Colombia. Rev Lasallista Investig. 2013;10:25-34.

37. Chinchilla M, Urbani B, Valerio I, Vanegas JC. Parasitosis intestinal en monos capuchinos cariblancos Cebus capucinus (Primates: Cebidae) de un área protegida en la provincia de Limón, noreste de Costa Rica. Int J Trop Biol. 2010;58:1335-46. https://doi.org/10.15517/RBT.V58I4.5416

38. Parr NA, Fedigan LM, Kutz SJ. A coprological survey of parasites in white-faced capuchins (Cebus capucinus) from Sector Santa Rosa, ACG, Costa Rica. Folia Primatol (Basel). 2013;84:102-14. https://doi.org/10.1159/000348287 
39. Müller B. Determinants of the diversity of intestinal parasite community in sympatric New World primates (Saguinus mystax, Saguinus fuscicollis, Callicebus cupreus). Disertación. Hannover: Universidad Veterinaria de Hannover; 2007. Fecha de consulta: 6 de enero de 2020. Disponible en: https://elib.tiho-hannover.de/receive/etd mods 00001869

40. Figueiroa Lyra De Freitas M, Bianque De Oliveira A, Dowell De Brito Cavalcanti M, Alves Oliveira R, Evêncio Sobrinho A. Perfil coproparasitológico de mamíferos silvestres en cautiverio en el estado de Pernambuco, Brasil. Parasitol día (Santiago). 2001;25:121-5. https://doi.org/10.4067/S0716-07202001000300009

41. Levecke B, Dreesen L, Dorny P, Verweij JJ, Vercammen F, Casaert S, et al. Molecular identification of Entamoeba spp. in captive nonhuman primates. J Clin Microbiol. 2010;48:2988-990. https://doi.org/10.1128/JCM.00013-10

42. Panayotova-Pencheva MS. Parasites in captive animals: A review of studies in some European zoos. Der Zoologische Garten. 2013;82:60-71. https://doi.org/10.1016/j.zoolgart.2013.04.005

43. Souvignet T, Giorgiadis M, Drouet B, Quintard B. EAZA Best Practice Guidelines CAPUCHIN MONKEYS (Sapajus and Cebus sp.). First edition. Mulhouse, France: Edtr. Mulhouse Zoo; 2019.

44. Barrião-Ruivo E, Stevenson MF. Guía de buenas prácticas de EAZA para Callitrichidae. $3^{\text {ra }}$ edición. Saint-Aignan, Francia: Edtr. Zoológico de Beauval; 2015.

45. Wolfensohn S, Honess P. Handbook of Primate Husbandry and Welfare. First edition. London Blackwell Publishing Ltd.; 2005. p. 168.

46. Stenzel DJ, Boreham PF. Blastocystis hominis revisited. Clin Microbiol Rev. 1996;9:563-84. https://doi.org/10.1128/CMR.9.4.563-584.1996

47. Ajjampur SS, Tan KS. Pathogenic mechanisms in Blastocystis spp. - Interpreting results from in vitro and in vivo studies. Parasitol Int. 2016;65:772-9. https://doi.org/10.1016/j.parint.2016.05.007

48. Skotarczak B. Genetic diversity and pathogenicity of Blastocystis. Ann Agric Environ Med. 2018;25:411-6. https://doi.org/10.26444/aaem/81315

49. Roberts T, Stark D, Harkness J, Ellis J. Update on the pathogenic potential and treatment options for Blastocystis sp. Gut Pathog. 2014;6:17. https://doi.org/10.1186/1757-4749-6-17

50. Betts EL, Gentekaki E, Thomasz A, Breakell V, Carpenter AI, Tsaousis AD. Genetic diversity of Blastocystis in non-primate animals. Parasitology. 2018;145:1228-34. https://doi.org/10.1017/S0031182017002347

51. Abe N, Nagoshi M, Takami K, Sawano Y, Yoshikawa H. A survey of Blastocystis sp. in livestock, pets, and zoo animals in Japan. Vet Parasitol. 2002;106:203-12. https://doi.org/10.1016/S0304-4017(02)00050-X

52. Abe N, Zhiliang W, Yoshikawa $\mathrm{H}$. Molecular characterization of Blastocystis isolates from primates. Vet Parasitol. 2003;113:321-5. https://doi.org/10.1016/S0304-4017(03)00081-5

53. Noël C, Dufernez F, Gerbod D, Edgcomb VP, Delgado-Viscogliosi P, Ho LC, et al. Molecular phylogenies of Blastocystis isolates from diferent hosts: Implications for genetic diversity, identification of species, and zoonosis. J Clin Microbiol. 2005;43:348-55. https://doi.org/10.1128/JCM.43.1.348-355.2005

54. Carvajal-Rincón A, Galvis-Moreno CE. Valoración médica en micos tití gris (Saguinus leucopus, Familia: Cebidae) en tres zoológicos colombianos. Tesis. Bogotá, D.C.: Universidad de La Salle; 2007. Fecha de consulta: 14 de diciembre de 2019. Disponible en: https://ciencia.lasalle.edu.co/medicina veterinaria/333/

55. Jiménez PA, Jaimes JE, Ramírez JD. Summary of Blastocystis subtypes in North and South America. Parasit Vectors. 2019;12:376. https://doi.org/10.1186/s13071-019-3641-2

56. Abe N. Molecular and phylogenetic analysis of Blastocystis isolates from various hosts. Vet Parasitol. 2004;120:235-42. https://doi.org/10.1016/j.vetpar.2004.01.003

57. Barrios-López NS. Estudio coproparasitario en primates no humanos del Parque Zoológico de Quilpué, V Región, Chile. Tesis. Valdivia: Universidad Austral de Chile; 2005. Fecha de consulta: 14 de diciembre de 2019. Disponible en: http://cybertesis.uach.cl/tesis/uach/2005/fvb276e/doc/fvb276e.pdf

58. Stensvold C R, Alfellani MA, Nørskov-Lauritsen S, Prip K, Victory EL, Maddox C, et al. Subtype distribution of Blastocystis isolates from synanthropic and zoo animals and identification of a new subtype. Int J Parasitol. 2009;39:473-9. https://doi.org/10.1016/j.ijpara.2008.07.006 
59. Cian A, El Safadi D, Osman M, Moriniere R, Gantois N, Benamrouz-Vanneste S, et al. Molecular epidemiology of Blastocystis sp. in various animal groups from two French zoos and evaluation of potential zoonotic risk. PLoS ONE. 2017;12:e0169659. https://doi.org/10.1371/journal.pone.0169659

60. Alfellani MA, Jacob AS, Perea NO, Krecek RC, Taner-Mulla D, Verweij JJ, et al. Diversity and distribution of Blastocystis sp. subtypes in non-human primates. Parasitology. 2013;140:96671. https://doi.org/10.1017/S0031182013000255

61. Stensvold CR, Alfellani M, Clark CG. Levels of genetic diversity vary dramatically between Blastocystis subtypes. Infect Genet Evol. 2012;12:263-73. https://doi.org/10.1016/j.meegid.2011.11.002

62. Scicluna SM, Tawari B, Clark C G. DNA Barcoding of Blastocystis. Protist. 2006;157:77-85. https://doi.org/10.1016/j.protis.2005.12.001

63. Bunton TE, Lowenstinaen LJ, Leininger DR. Invasive trichomoniasis in a Callicebus moloch. Vet Pathol. 1983;20:491-4. https://doi.org/10.1177/030098588302000412

64. Smejkalová P, Petrželková KJ, Pomajbíková K, Modrý D, Čepička I. Extensive diversity of intestinal trichomonads of non-human primates. Parasitology. 2012;139:92-102. https://doi.org/10.1017/S0031182011001624

65. Culberson DE, Pindak FF, Gardner WA, Honigberg BM. Trichomonas mobilensis n. sp. (Zoomastigophorea Trichomonadida) from the Bolivian squirrel monkey Saimiri boliviensis boliviensis. J Protozool. 1986;33:301-4. https://doi.org/10.1177/030098588902600207

66. Mantini C, Souppart L, Noël C, Duong TH, Mornet M, Carroger G, et al. Molecular characterization of a new Tetratrichomonas species in a patient with empyema. J Clin Microbiol. 2009;47:2336-9. https://doi.org/10.1128/JCM.00353-09

67. Kutisova K, Kulda J, Cepicka I, Flegr J, Koudela B, Teras J, et al. Tetratrichomonads from the oral cavity and respiratory tract of humans. Parasitology. 2005;131:309-19. https://doi.org/10.1017/S0031182005008000

68. Bastos BF, Brener B, de Figueiredo MA, Leles D, Mendes-de-Almeida F. Pentatrichomonas hominis infection in two domestic cats with chronic diarrea. JFSM Open Rep. 2018;4:2055116918774959. https://doi.org/10.1177/2055116918774959

69. Saha R, Singal A, Kaushik S, Das S. Pentatrichomonas hominis in an immunosuppressed patient with enteric manifestations. Eastern Journal of Medical Sciences. 2017;2:37-8. https://doi.org/10.32677/EJMS.2017.v02.102.005

70. Li WC, Wang K, Zhang W, Wu J, Gu YF, Zhang XC. Prevalence and molecular characterization of intestinal Trichomonads in pet dogs in East China. Korean J Parasitol. 2016;54:703-10. https://doi.org/10.3347/kjp.2016.54.6.703

71. Mostegl MM, Wetscher A, Richter B, Nedorost N, Dinhopl N, Weissenböck H. Detection of Tritrichomonas foetus and Pentatrichomonas hominis in intestinal tissue specimens of cats by chromogenic in situ hybridization. Vet Parasitol. 2012;183:209-14. https://doi.org/10.1016/j.vetpar.2011.07.050

72. Jongwutiwes S, Silachamroon U, Putaporntip C. Pentatrichomonas hominis in empyema thoracis. Trans R Soc Trop Med Hyg. 2000;94:185-6. https://doi.org/10.1016/S0035-9203(00)90270-0

73. Jo SH, Choi TY, Kim WB, Lee DW, Kang DY. A case report of Trichomonas hominis in ascitic and pleural fluids. K J Clin Pathol. 1992;12:79-83.

74. Berrilli F, Prisco C, Friedrich KG, Di Cerbo P, Di Cave D, De Liberato C. Giardia duodenalis assemblages and Entamoeba species infecting non-human primates in an Italian zoological garden: Zoonotic potential and management traits. Parasit Vectors. 2011;12:199. https://doi.org/10.1186/1756-3305-4-199

75. Verweij JJ, Vermeer J, Brienen EA, Blotkamp C, Laeijendecker D, van Lieshout L, et al. Entamoeba histolytica infections in captive primates. Parasitol Res. 2003;90:100-3. https://doi.org/10.1007/s00436-002-0808-z

76. Verweij JJ, Polderman AM, Clark CG. Genetic variation among human isolates of uninucleated cyst-producing Entamoeba species. J Clin Microbiol. 2001;39:1644-6. https://doi.org/10.1128/JCM.39.4.1644-1646.2001

77. Sargeaunt PG, Patrick S, O'Keeffe D. Human infections of Entamoeba chattoni masquerade as Entamoeba histolytica. Trans R Soc Trop Med Hyg. 1992;86:633-4.

https://doi.org/10.1016/0035-9203(92)90162-6 
78. Chinchilla-Carmona M, Guerrero-Bermúdez O, Gutiérrez-E GA, Sánchez-Porras R, Rodríguez-Ortiz B. Parásitos intestinales en monos congo Alouatta palliata (Primates: Cebidae) de Costa Rica. Rev Biol Trop. 2005;53:437-45.

79. Stedman NL, Munday JS, Esbeck R, Visvesvara GS. Gastric amebiasis due to Entamoeba histolytica in a dama wallaby (Macropus eugenii). Vet Pathol. 2003;40:340-2. https://doi.org/10.1354/vp.40-3-340

80. Einarsson E, Ma'ayeh S, Staffan SG. An up-date on Giardia and Giardiasis. Curr Opin Microbiol. 2016;34:47-52. https://doi.org/10.1016/j.mib.2016.07.019

81. Thompson RCA. The zoonotic significance and molecular epidemiology of Giardia and giardiasis. Vet Parasitol. 2004;126:15-35. https://doi.org/10.1016/j.vetpar.2004.09.008

82. Thompson RC, Monis P. Giardia-from genome to proteome. Adv Parasitol. 2012;78:57-95. https://doi.org/10.1016/B978-0-12-394303-3.00003-7

83. Levecke B, Geldhof P, Claerebout E, Dorny P, Vercammen F, Cacciò SM, et al. Molecular characterisation of Giardia duodenalis in captive non-human primates reveals mixed assemblage A and B infections and novel polymorphisms. Int J Parasitol 2009;39:1595-601. https://doi.org/10.1016/i.ijpara.2009.05.013

84. Kramer JA, Hachey AM, Wachtman LM, Mansfield KG. Treatment of Giardiasis in common marmosets (Callithri jacchus) with tinidazole. Comp Med. 2009;59:174-9.

85. Chagas CR, González IH, Salgado PA, Rodrigues B, Ramos PL. Giardia spp., ten years of parasitological data in the biggest zoo of Latin America. Ann Parasitol. 2019;65:35-51. https://doi.org/10.17420/ap6501.181

86. Martínez-Díaz RA, Sansano-Maestre J, Martínez-Herrero MC, Ponce-Gordo F, GómezMuñoz MT. Occurrence and genetic characterization of Giardia duodenalis from captive nonhuman primates by multi-locus sequence analysis. Parasitol Res 2011;109:539-44. https://doi.org/10.1007/s00436-011-2281-z

87. Opara MN, Osuji CT, Opara JA. Gastrointestinal parasitism in captive animals at the Zoological Garden, Nekede Owerri, Southeast Nigeria. Rep Opinion. 2010;2:21-8.

88. de Lucio A, Martínez-Ruiz R, Merino FJ, Bailo B, Aguilera M, Fuentes I, et al. Molecular genotyping of Giardia duodenalis isolates from symptomatic individuals attending two major public hospitals in Madrid, Spain. PLoS ONE. 2015;10:e0143981. https://doi.org/10.1371/journal.pone.0143981

89. Tungtrongchitr A, Sookrung N, Indrawattana N, Kwangsi S, Ongrotchanakun J, Chaicumpa W. Giardia intestinalis in Thailand: Identification of genotypes. J Health Popul Nutr. 2010;28:42-52. https://doi.org/10.3329/jhpn.v28i1.4522

90. Heyworth MF. Giardia duodenalis genetic assemblages and hosts. Parasite. 2016;23:13. https://doi.org/10.1051/parasite/2016013

91. Bethony J, Brooker S, Albonico M, Geiger SM, Loukas A, Diemert D, et al. Soil-transmitted helminth infections: Ascariasis, trichuriasis, and hookworm. Lancet. 2006;367:1521-32. https://doi.org/10.1016/S0140-6736(06)68653-4

92. Eo KY, Seo MG, Lee HH, Jung YM, Kwak D, Kwon OD. Severe whipworm (Trichuris spp.) infection in the hamadryas baboon (Papio hamadryas). J Vet Med Sci. 2019;81:53-6. https://doi.org/10.1292/jvms.17-0568

93. Ghai RR, Simons ND, Chapman CA, Omeja PA, Davies TJ, Ting N, et al. Hidden population structure and cross-species transmission of whipworms (Trichuris sp.) in humans and nonhuman primates in Uganda. PLoS Negl Trop Dis. 2014;8:e3256. https://doi.org/10.1371/journal.pntd.0003256

94. Albani A, De Liberato C, Wahid I, Berrilli F, Riley EP, Cardeti G, et al. Preliminary assessment of gastrointestinal parasites in two wild groups of endangered Moor Macaques (Macaca maura) from Sulawesi. Int J Primatol. 2019;40:671-86. https://doi.org/10.1007/S10764-019-00114-W

95. Agostini I, Vanderhoeven E, Beldomenico PM, Pfoh R, Notarnicola J. First coprological survey of helminths in a wild population of black capuchin monkeys (Sapajus nigritus) in northeastern Argentina. Mastozool Neotrop. 2018;25:269-81.

https://doi.org/10.31687/saremMN.18.25.2.0.11

96. de Araújo FG, Bicca-Marques JC, Calegaro-Marques C, de Farias EM, de O Azevedo MA. On the occurrence of parasites in free-ranging Callitrichids. Neotrop Primates. 1995;3:46-7

97. Rivero-Fernández J. Especies de Trichuris aisladas de primates de parques zoológicos de España. Tesis. Sevilla: Universidad de Sevilla; 2018. 
98. Bölükbaş CS, Pekmezci GZ, Gürler AT, Açici M, Umur Ş. Zoonotic Trichuris trichiura infections in non-human primates at Samsun Zoo, Turkey: First molecular characterization. Kafkas Univ Vet Fak Derg. 2014;20:161-4. https://doi.org/10.9775/kvfd.2013.9615

99. Hawash MBF, Andersen LO, Gasser RB, Stensvold CR, Nejsum P. Mitochondrial genome analyses suggest multiple Trichuris species in humans, baboons, and pigs from different geographical regions. PLoS Negl Trop Dis. 2015;9:e0004059. https://doi.org/10.1371/journal.pntd.0004059

100. Viney ME, Lok JB. The biology of Strongyloides spp. Wormbook. 2015;16:1-17. https://doi.org/10.1895/wormbook.1.141.2

101. Thamsborg SM, Ketzis J, Horii Y, Matthews JB. Strongyloides spp. infections of veterinary importance. Parasitology. 2017;144:274-84. https://doi.org/10.1017/S0031182016001116

102. Barratt JLN, Lane M, Talundzic E, Richins T, Robertson G, Formenti F, et al. A global genotyping survey of Strongyloides stercoralis and Strongyloides fuelleborni using deep amplicon sequencing. PLoS Negl Trop Dis. 2019;13:e0007609. https://doi.org/10.1371/journal.pntd.0007609

103. Nutman TB. Human infection with Strongyloides stercoralis and other related Strongyloides species. Parasitology. 2017;144:263-73. https://doi.org/10.1017/S0031182016000834

104. Jaleta TG, Lok JB. Advances in the molecular and cellular biology of Strongyloides spp. Curr Trop Med Rep. 2019;6:161-78. https://doi.org/10.1007/s40475-019-00186-X

105. Tantaleán VM, Sánchez P N, Perea CMI. Infección natural por Strongyloides stercoralis en Pithecia monachus (Primates, Pitheciidae). Primer reporte en el Perú. Rev Inv Vet Perú. 2018;29:1386-90. https://doi.org/10.15381/rivep.v29i4.15197

106. Terashima A, Canales M, Tello R, Mas-Coma S, Esteban G, Bargues M, et al. Strongyloides fuelleborni: reporte del primer caso clínico en el Perú. Diagnóstico 2000;39. Fecha de consulta: 12 de enero de 2020. Disponible en: http://www. fihu.org.pe/revista/numeros/2000/ julago00/199-203.html

107. Flores-Casas N, Olivo-Inga Y, Saavedra-Alemán Z, Grados-Castillo J. Casos Clínicos. Infección diseminada por Strongyloides fuelleborni. Boletín de la Sociedad Peruana de Medicina Interna. 2001;14. Fecha de consulta: 12 de enero de 2020. Disponible en: http://sisbib.unmsm.edu.pe/bvrevistas/spmi/v14n1/infecci\%C3\%B3n.htm

108. Zerpa-Larrauri R, Espinoza-Blanco Y, Náquira C. Ciclo biológico de Strongyloides fuelleborni: imágenes y videos. Rev Peru Med Exp Salud Pública. 2014;31:390-2.

109. Torres Freile MF. Determinación de la prevalencia del parásito intestinal Prosthenorchis sp. en primates del nuevo mundo en los zoológicos y centros de rescate: Zoológico de Tarqui, Paseo de los Monos, Yanacocha y Misahualli. Tesis. Quito: Universidad de las Américas; 2014

110. Botero LC, Fernández A, Forero N, Rosas S, Soler-Tovar D. Análisis retrospectivo de las enfermedades parasitarias del mono ardilla (Saimiri sciureus) en dos condiciones ex situ en el noroccidente de los Andes suramericanos. Rev Med Vet. 2011;22:85-93. https://doi.org/10.19052/mv.557

111. Tenorio-Mati VL, Raso P, de Melo AL. Strongyloides stercoralis infection in marmosets: Replication of complicated and uncomplicated human disease and parasite biology. Parasit Vectors. 2014;7:579. https://doi.org/10.1186/s13071-014-0579-2

112. Solórzano-García B, Pérez-Ponce de León G. Helminth parasites of howler and spider monkeys in México: Insights into molecular diagnostic methods and their importance for zoonotic diseases and host conservation. Int J Parasitol Parasites Wildl. 2017;6:76-84. https://doi.org/10.1016/j.ijppaw.2017.04.001

113. Hasegawa H, Sato H, Fujita S, Nguema PP, Nobusue K, Miyagi K, et al. Molecular identification of the causative agent of human strongyloidiasis acquired in Tanzania: Dispersal and diversity of Strongyloides spp. and their hosts. Parasitol Int. 2010;59:407-13. https://doi.org/10.1016/j.parint.2010.05.007

114. Dacal E, Saugar JM, Soler T, Azcárate JM, Jiménez MS, Merino FJ, et al. Parasitological versus molecular diagnosis of strongyloidiasis in serial stool samples: how many? J Helminthol. 2018;92:12-6. https://doi.org/10.1017/S0022149X17000050

115. Dorris M, Viney ME, Blaxter ML. Molecular phylogenetic analysis of the genus Strongyloides and related nematodes. Int J Parasitol. 2002;32:1507-17. https://doi.org/10.1016/S0020-7519(02)00156-X 
116. Eberhard ML, Owens JR, Bishop HS, de Almeida ME, da Silva AJ. Cyclospora spp. in drills, Bioko Island, Equatorial Guinea. Emerg Infect Dis. 2014;20:510-1.

https://doi.org/10.3201/eid2003.131368

117. Legesse M, Erko B. Zoonotic intestinal parasites in Papio anubis (baboon) and Cercopithecus aethiops (vervet) from four localities in Ethiopia. Acta Trop. 2004;90:231-6. https://doi.org/10.1016/j.actatropica.2003.12.003

118. Marangi M, Koehler AV, Zanzani SA, Manfredi MT, Brianti E, Giangaspero A, et al. Detection of Cyclospora in captive chimpanzees and macaques by a quantitative PCR-based mutation scanning approach. Parasit Vectors. 2015;8:274. https://doi.org/10.1186/s13071-015-0872-8

119. Li N, Ye J, Arrowood MJ, Ma J, Wang L, Xu H, et al. Identification and morphologic and molecular characterization of Cyclospora macacae n. sp. from rhesus monkeys in China. Parasitol Res. 2015;114:1811-6. https://doi.org/10.1007/s00436-015-4367-5

120. Roncancio-Duque N, Benavides Montaño JA. Parásitos intestinales en poblaciones pequeñas y aisladas de Mono aullador rojo (Alouatta seniculus) y Mono araña café (Ateles hybridus), Atelidae - Primates en el Magdalena Medio, Colombia. Veterinaria y Zootecnia. 2013;7:71-89.

121. Almeria S, Cinar HN, Dubey JP. Cyclospora cayetanensis and cyclosporiasis: An update. Microorganisms. 2019;7:E317. https://doi.org/10.3390/microorganisms7090317

122. Eberhard ML, da Silva AJ, Lilley BG, Pieniazek NJ. Morphologic and molecular characterization of new Cyclospora species from Ethiopian monkeys: C. cercopitheci sp.n. C. colobi sp.n., and C. papionis sp.n. Emerg Infect Dis. 1999;5:651-8. https://doi.org/10.3201/eid0505.990506

123. Eberhard ML, Njenga MN, DaSilva AJ, Owino D, Nace EK, Won KY, et al. A survey for Cyclospora spp. in Kenyan primates, with some notes on its biology. J Parasitol. 2001;87:1394-7. https://doi.org/10.1645/0022-3395(2001)087[1394:ASFCSI]2.0.CO;2 